\title{
Fatores associados à infecção ou contaminação por germe multirresistente em pacientes clínicos de hospital secundário do interior do Brasil $100 \%$ SUS
}

\author{
Rohr, D.; Diogo, L.P.; Bahlis, L.F.; Waldemar, F.S.; Soares, V.S.; Fonseca, F.; \\ Wajner, A.;
}

Apresentador: Fernando Waldemar

\section{Resumo}

Introdução: A infecção e a contaminação por germe multirresistentes (GMR) estão associado a desfechos clínicos desfavoráveis, aumento de custos e do tempo de internação. Para reduzir a infecção e contaminação por GMR é necessário a identificação de seus fatores de riscos. Objetivos: identificar fatores associados à infecção ou contaminação por GMR em pacientes clínicos internados. Método: foi realizada coorte retrospectiva dos pacientes internados em enfermaria clínica do Hospital Montenegro. Os dados foram retirados da base de dados do serviço de medicina hospitalar, que contém informações sócio-demográficas e clínicas dos pacientes. As informações são coletas no momento da alta por coletadora treinada, por meio de revisão de prontuário e complementadas pelo médico assistente. Após, é feita revisão dos dados por médico independente para conferência do preenchimento. Os dados são digitados em planilha Excel, com conferência por outro membro da equipe, sendo posteriormente importados para SPSS para análise estatística. Foi realizada estatística descritiva, além de regressão logística método stepwise forward. Resultados: o período de coleta foi de maio de 2013 a abril de 2014. O total de pacientes analisados foi de 1537. O critério de infecção por GMR se deu pela cultura positiva e de contaminação pela positividade do Swab de vigilância em qualquer momento da internação. A cultura por GMR foi positiva em $124(8,1 \%)$ dos pacientes e o Swab de vigilância em $167(10,9 \%)$. Os fatores de risco encontrados em nossa população para infecção por GMR foram: internação superior a 7 dias (OR 6,12 IC 3,19-11,9 $\mathrm{p} ?<0,0001)$ necessidade do uso e ATB $(5,15$ IC $1,15-22,3 \mathrm{p} ?<0,001)$ infecção do trato respiratório $(2,05$ IC1,9-3,87 $\mathrm{p} ?<0,0001)$ e passagem por leito de UTI $(2,54$ IC $1,28-5,50$ p?=0,007). Para positividade nos Swabs de vigilância os Fatores de riscos encontrados foram: Internação superior a sete dias (OR 2,24 IC 2,0-5,24 p? <0,0001) necessidade do uso de ATB (OR 2,73 IC 1,3-5,6 p? <0,01) paciente oriundo de instituição geriátrica (OR 6,79 IC 2,90$15,87 \mathrm{p} ?<0,001)$ paciente transferido de outro hospital (OR 5,55 IC 2,10-14,4 p? <0,001) Conclusão. A identificação do problema e de seus fatores de risco auxilia na tomada de decisão para as estratégias preventivas. Dados de hospitais terciários podem não ser iguais a de hospitais secundários fora das grandes metrópoles. Acreditamos que nosso acrescenta informações neste contexto a comunidade acadêmica e hospitalar.

\section{Referência:}

Rohr, D.; Diogo, L.P.; Bahlis, L.F.; Waldemar, F.S.; Soares, V.S.; Fonseca, F.; Wajner, A.;. Fatores associados à infecção ou contaminação por germe multirresistente em pacientes clínicos de hospital secundário do interior do Brasil 100\% SUS. In: II Congresso Brasileiro de Medicina Hospitalar - II CBMH [= Blucher Medical Proceedings, vol.1, num.5] São Paulo: Editora Blucher, 2014. p.90

DOI 10.5151/medpro-II-cbmh-089 